\title{
СВЯТИТЕЛЬ ЛУКА (ВОЙНО-ЯСЕНЕЦКИЙ) О НАУКЕ И РЕЛИГИИ
}

\section{Священник Павел Лизгунов}

\author{
кандидат богословия \\ проректор по учебной работе Московской духовной академии \\ 141300, Сергиев Посад, Свято-Троицкая Сергиева Лавра, Академия \\ lizgunov@gmail.com
}

Для цитирования: Лизгунов П., свящ. Святитель Лука (Войно-Ясенецкий) о науке и религии // Вопросы богословия. 2020. № 2 (4). С. 62-72. DOI: 10.31802/PWG.2020.4.2.003

\begin{abstract}
Аннотация
УДК: 271-1:001(091)

Статья раскрывает взгляды святителя Луки на соотношение науки и религии, изложенные в его произведениях «Дух, душа и тело» и «Наука и религия». Свт. Лука показывает, что между наукой и религией нет и не может быть коренных противоречий в виду очень ограниченного пересечения областей одной и другой; показывает, что во многих отношениях наука и религия взаимно дополняют друг друга. В своих рассуждениях он приводит ряд традиционных и некоторые оригинальные аргументы.
\end{abstract}

Ключевые слова: свт. Лука (Войно-Ясенецкий), Дух душа и тело, христианство, наука и религия, апологетика, естественные науки, витализм, религиозность учёных, духовный мир. 


\section{Введение}

Диалог науки и религии (в частности, христианской религии) - явление не новое. Ещё в древности, сразу после появления христианства в пределах Римской империи эпохи эллинизма, оно было воспринято этой передовой цивилизацией мира как явление чуждое. Представители античной учёности критиковали и высмеивали христианство как варварские бредни и предрассудки. Понадобились десятилетия и века трудов христианских апологетов, некоторые из которых были светочами учёности своего времени, для того, чтобы переломить это представление.

В Средние века в Европе христианские монастыри были оплотом науки, множество выдающихся мыслителей были так или иначе близки к церковному служению: являлись носителями священного сана, насельниками и аббатами монастырей. Из монастырей выросли многие европейские университеты. Христианство дисциплинировало мысль, побуждало к исследованию Божьего мира, убеждающему в величии и мудрости Божественного замысла. Однако оно же накладывало серьёзные ограничения на направления и глубину многих исследований, о чём мы больше всего знаем в связи с такими именами, как Дж. Бруно и Г. Галилей.

В Новое время наука выходит из монастырей в мир и постепенно обособляется от религии. В первую очередь это связано с потрясающими успехами естественных наук. С этих пор начинается время диалога науки и религии - диалога, который подчас перерастает в ожесточённый спор.

Конфликт между наукой и религией часто искажается и преувеличивается, причём, как правило, со стороны людей, далёких как от одного, так и от другого, - во всяком случае, далёких от серьёзных научных изысканий или глубоких религиозных познаний и опыта. Вульгаризированно этот спор выражался формулами типа: «Гагарин в космос летал, Бога не видал» или: «Единственная подлинно научная философия марксизма-ленинизма свидетельствует, что Бога нет».

Однако не менее ошибочным будет и противоположная крайность - говорить, что никакого напряжения между наукой и религией нет и быть не может, поскольку наука это - область разума, а религия - область сердца; религия говорит только о Боге, душе и небесном мире, наука - о земном.

Так можно было бы утверждать, если бы христианское учение было чистой метафизикой. Однако христианство и наука содержат области 
пересечений: вопросы происхождения мира, антропологии, истории Ближнего Востока. При этом с ходом веков наука охватывает всё новые сферы, традиционно принадлежавшие одной лишь религии (психология, психотерапия, этика и т. п.), и области пересечений постепенно расширяются, что вынуждает религию искать ответы на новые вопросы, а в некоторых случаях - пересматривать свою доктрину.

То есть напряжение между этими двумя областями человеческих знаний существует и требует своего разрешения. Иногда, чаще по идеологическим причинам, это напряжение обостряется до конфликта.

\section{1. Отсутствие фундаментальных противоречий}

Свт. Лука Войно-Ясенецкий волею судьбы (а выражаясь по-христиански - Промыслом Божиим) был вынужден напрямую столкнуться с этим вопросом. Будучи выдающимся хирургом, профессором, он хоть и не был естествоиспытателем, профессиональным химиком, физиком или биологом, но, несомненно, был хорошо и разносторонне осведомлён о достижениях естественных наук своего времени. Будучи человеком глубочайшей религиозности, который в эпоху тяжелейших гонений на веру принимает сан священника, затем епископа, читает лекции в рясе с крестом или панагией, оперирует больных, пронося свою веру через тюрьмы и лагеря, он сталкивается с грубо материалистической критикой религии - критикой, иногда принимающей самые вульгарные формы (наподобие упомянутых ранее), иногда - более профессиональной и изощрённой. И как человек осведомлённый и заинтересованный, он не мог не пытаться давать на неё свой ответ.

Основные произведения святителя, посвящённые соотношению науки и религии - это, во-первых, брошюра, которая так и называется: «Наука и религия» и, во-вторых, более известная и популярная книга под названием «Дух, душа и тело». В первой он рассматривает вопрос соотношения науки и религии в общем, во второй - пытается доказать центральную религиозную мысль о существовании невидимого духовного мира.

В своих книгах святитель прежде всего стремится показать, что наука никак не противоречит религии. Во-первых, конфликт между ними сильно преувеличен. Дж. Бруно пострадал не за защиту гелиоцентрической системы Коперника, а более за критику монастырских доходов, т. е. по экономическим причинам. При этом Библия вовсе не стоит на ошибочных позициях геоцентризма, с которым боролись Бруно и Галилей, 
или на столь же ошибочных позициях гелиоцентризма, которые они отстаивали, - но на позициях теоцентризма и христоцентризма ${ }^{1}$.

Относительно знамени научного атеизма его времени, теории эволюции Ч. Дарвина свт. Лука говорит, что, во-первых, она является только гипотезой, а не доказанной теорией, поскольку, в частности, так и не были найдены убедительные примеры перехода от животного к человеку. Во-вторых, даже будучи верной, эта теория не противоречит христианскому откровению, а лишь корректирует его традиционно сложившуюся интерпретацию. В-третьих, он указывает на то, что сам Ч. Дарвин был религиозным человеком, и его посетители вынуждены были дожидаться пока он не завершит молитву и не сможет их принять ${ }^{2}$.

«Откуда же происходит распространённое среди студентов, и вообще образованных людей, мнение, что наука противоречит религии? вопрошает святитель - и отвечает на этот вопрос. - Его причина в поверхностном знании как в области науки, так и в области религии, и этим подтверждается мысль: “Знание приводит к Богу, полузнание удаляет от него”. Полузнание - бич нашего времени: оно-то и создаёт названное только что предубеждение» ${ }^{3}$.

Свт. Лука говорит о том, что наука и религия имеют разные сферы исследования. Наука есть система достигнутых знаний о наблюдаемых нами явлениях действительности. При этом важно помнить, что наука не изучает сам окружающий мир как таковой, но лишь наблюдаемые нами его проявления. Атом, электрон, само понятие материи, энергия, лежащая в её основе - это не вещи как они есть, но некая фикция, гипотетический способ описать наблюдаемый учёным опыт. Подобные понятия существуют некоторое время, пока под влиянием новых опытов не изобретается новая, более тонкая фикция ${ }^{4}$.

Религия же - это отношение к Абсолютному, отношение к Богу. Центр религии - это непосредственное религиозное, молитвенное переживание человеческой души.

Т. е. самые сердцевинные, главные области науки и религии не пересекаются. В этом смысле, по словам святителя, «Между религией и наукой может быть столько же противоречий, сколько их между математикой и музыкой или между математикой и любовью»5.

1 Лука (Войно-Ясенецкий), архиеп. Наука и религия // Лука (Войно-Ясенецкий), архиеп. Избранные творения. М., 2010. С. 425-426.

2 Там же. С. 425-426, 396.

3 Там же. С. 384.

4 Там же. С. 382.

5 Там же. С. 383. 
Сравнивать науку можно только с одной из сторон религии - второстепенной, интеллектуальной стороной - с её утверждениями о действительности. При этом главные утверждения христианской веры: Бог существует, Христос воскрес, душа бессмертна - также касаются сущностей, лежащих вне пределов науки. Сравнивать науку с религией можно только в случае второстепенных высказываний последней, касающихся творения мира, человека, отдельных исторических событий ${ }^{6}$

\section{2. Религиозность великих учёных}

Свт. Лука широко использует очень распространённый в христианской апологетике аргумент о личной религиозности множества выдающихся учёных, писателей, философов: Исаака Ньютона, Карла Линнея, Чарльза Дарвина, Луи Пастера, Блеза Паскаля, Николая Ивановича Пирогова, Альберта Эйнштейна и многих других ${ }^{7}$.

Хотя в настоящее время этот довод кажется избитым и, может быть, не столь убедительным, т. к. вера учёных могла быть обусловлена их воспитанием, эпохой, а среди нобелевских лауреатов XX в. немало атеистов, однако нельзя полностью отказывать этому аргументу в убедительности. Современному человеку совсем не лишним будет знать, что Николай Коперник был священником, Исаак Ньютон писал толкования на книги Нового Завета ${ }^{8}$, а Блез Паскаль - апологетические книги в защиту веры ${ }^{9}$. Как минимум это опровергает вульгарное, но вполне живучее представление об учёных как о героях мысли в невежественном мире средневекового церковного мракобесия. А если оценить этот факт более объективно и непредвзято: люди смелой, глубокой и независимой мысли во время острых религиозных споров, во время возникновения атеизма защищали религию, имели личный духовный опыт, с восторгом писали о Библии, - этот факт заставляет задуматься.

Как писал Вольтер об изучении мира: «Нужно быть слепым, чтобы не быть ослеплённым этой картиной, нужно быть глупцом, чтобы не признать её Творца, нужно быть безумцем, чтобы перед Ним не преклониться» ${ }^{10}$.

6 Лука (Войно-Ясенецкий), архиеп. Наука и религия. С. 383.

7 Там же. С. 423-426.

8 Ньютон И. Толкования на пророчества Даниила и Апокалипсис Иоанна Богослова. СПб., 2018.

9 Паскаль Б. Мысли. СПб., 2017.

10 Лука (Войно-Ясенецкий), архиеп. Наука и религия. С. 422. 
От опровержения представления о противоположности религии и науки свт. Лука переходит к положительным аргументам, показывая, что подлинная религия и подлинное христианство не только не противоречит, но подтверждается наукой и способствует её развитию.

Известны аргументы, что языческое пантеистическое отношение к миру мешало исследовать и препарировать его, христианство же в силу своего монотеизма дозволяет и даже поощряет разумное исследование. Вебер одной из причин резкого скачка в развитии экономики, а также и науки и техники видит переход от католицизма к более земному протестантизму ${ }^{11}$.

Свт. Лука в этом вопросе также высказывает свои, достаточно интересные мысли.

Во-первых, он говорит о том, что естественнонаучные утверждения Библии очень глубоки и выдерживают соприкосновения с данными астрономии или геологии - в отличие, например, от некоторых наивных утверждений индуизма, зороастризма или ислама. К примеру, в отличие от представлений древних, Библия не говорит о небесном своде, на котором крепятся звёзды, но говорит о том, что небо - это протяжённая среда, отделяющая воды вверху от вод внизу (т. е. вещество от вещества). Библия не повторяет традиционного для древних представления об опорах земли, но утверждает, что Бог «повесил землю ни на чем». В ней можно найти намёки на закон сохранения энергии, на атомную теорию вещества и многие другие позднейшие открытия. По словам святителя, можно смело согласиться с французским физиком Биа (17741861), который сказал: «Или Моисей имел столь же глубокую научную опытность, какою обладает наш век, или он был вдохновлён свыше» ${ }^{12}$.

Святитель также указывает на подтверждение наукой многих библейских утверждений: о существовании праязыка всего человечества, о Вавилонской башне, указывает на многие археологические находки, подтверждающие библейское летописания и даже библейские пророчества о будущем ${ }^{13}$.

«Религия не противоречит науке, но религия движет науку, - говорит святитель. - религиозный опыт открывает многим реальное непосредственное бытие Того, чьё присутствие подсказывали и мысль, и откровения красоты, и сознание собственного несовершенства» ${ }^{14}$.

11 Вебер М. Протестантская этика и дух капитализма // Вебер М. Избранные произведения. М., 1990. С. 184-208.

12 Лука (Войно-Ясенецкий), архиеп. Наука и религия. С. 389.

13 Там же. С. 390.

14 Там же. С. 391. 
Религия пробуждает и поощряет дух исследования, пробуждает любовь к жизни, к природе, к человеку, освещая их светом вечного, непреходящего смысла. Подлинная религия воспитывает важнейшие качества исследователя: самоотверженный труд, веру в конечный результат. Более того, в религиозном опыте мы вступаем в контакт с вечным Разумом, просвещающим разум исследователя ${ }^{15}$.

Очень интересно утверждение свт. Луки о том, что развитию науки послужило и такое чисто религиозное, христианское качество религии, как смирение. Смирение - это самоумаление человека перед Богом и Его творением, в противоположность гордому самовозвышению человека над окружающим миром. По мысли святителя, именно этой христианской добродетели наука обязана переходом от дедуктивного метода исследования, когда выводы делаются из заранее принятых положений, к индуктивному методу, когда общее суждение выводится из частных фактов. Именно этот поворот к смиренному преклонению перед действительностью обусловил переход от бесплодного рационализма XVII в. к многоплодному (в естественнонаучной сфере) эмпиризму последующих веков ${ }^{16}$.

\section{3. Бытие духовного мира}

Ещё одним обширным блоком аргументов свт. Луки в защиту религии является стремление доказать существование духа и духовного мира, отличного от мира материального.

Во-первых, святитель Лука приводит ссылки на многочисленные происшествия, вырывающиеся из рамок обыденного порядка вещей. При этом он перемежает свидетельства Евангелия и житий христианских святых историями из жизни медиумов, спиритов, гипнотизёров, а также экстремальными случаями из опыта обычных людей, которые все вместе несомненно свидетельствуют о наличии у человека иных, не исследованных способов восприятия ${ }^{17}$.

Подборки подобных историй, как правило, вызывают усмешку у скептика - и нередко усмешку оправданную, потому что люди, занимающиеся спиритизмом и подобными явлениями, как правило, склонны

15 Лука (Войно-Ясенецкий), архиеп. Наука и религия. С. 392.

16 Там же.

17 Лука (Войно-Ясенецкий), архиеп. Дух, душа и тело // Лука (Войно-Ясенецкий), архиеп. Избранные творения. С. 363-370. 
к экзальтации, часто выдают желаемое за действительное, а нередко прибегают и к прямым фальсификациям и подлогам. Пристрастием к сборникам подобных историй грешат и многочисленные эзотерики, и уфологи, и иные любители тайных доктрин.

Однако святитель проявляет здесь должную для христианина и для учёного трезвость, аккуратно отбирает наиболее достоверные случаи и не следует выводам их авторов, но проводит лишь одну мысль о наличии иных способов восприятия, помимо обычных пяти чувств и, следовательно, о наличии духовного мира, не знакомого науке и повседневному опыту. В таком контексте эти истории выглядят уместно и убедительно. Свойственное для строгого материалиста стремление все подобные явления чужой и даже своей жизни редуцировать и объяснить самовнушением, играми подсознания и т. п. явлениями - попахивают догматизмом, за который так любят порицать религию, и выглядят намного менее убедительными, чем простое признание того несомненного факта, что наука знает о мире и человеке не всё.

Святитель прибегает к аргументам эстетического характера, когда говорит, что одухотворённость является не только свойством человека, но и свойством природы, даже неживой природы.

Он говорит так:

Многосторонне значение красоты в природе, и, конечно, она не исчерпывается только целями полового подбора. Не только для привлечения самок одеты ярким и красивым оперением и прекрасно поют самцы птиц. Не только для привлечения насекомых, несущих на себе оплодотворяющую пыльцу, сияют красотой и благоуханием цветы. Великие красоты природы имеют, конечно, не одни утилитарные цели ${ }^{18}$.

Духом грандиозной силы и мощи проникнуты окутанные мрачными тучами массивы гор и скал, гонимые ураганом громады волн океана, штурмующие прибрежные скалы... Высшую ценность нравственной красоты и мерзость безобразия являет природа в кротких и чистых глазах добрых людей, в отталкивающем виде злодеев и бесчестных.

И если так очевидно, что в этих формах нравственной красоты и безобразия мы реально воспринимаем излучение духа красоты и духа злобы, волнующие сердца наши, то не вправе ли мы сказать, что в основе тех глубоких духовных восприятий, которые получаем мы от красоты и безобразия форм неорганической природы, лежат подобные же воздействия на нас духовной энергии, присущей всей природе? ${ }^{19}$

18 Лука (Войно-Ясенецкий), архиеп. Дух, душа и тело. С. 346-347.

19 Там же. С. 347. 


\section{4. Жизненная сила}

Аргументом в пользу существования духовного измерения считает святитель, в частности, присущую всему живому непостижимую жизненную силу: рыба, годами замороженная во льду, оживает, прорастает семя, тысячелетиями пролежавшее в египетской мумии или экспериментально высушенное при $40^{\circ} \mathrm{C}$ в течение 6 месяцев и замороженное на недели до $-250^{\circ} \mathrm{C}$.

«Если так очевидно, что временная смерть семян и животных не мешает тому, чтобы снова возникла в них жизнь, то не имеем ли мы права утверждать, что это невозможно без проявления в них какой-то неведомой нам силы, жизненной энергии, совершенно не поддающейся воздействию вредных агентов, уничтожающих жизнь семян и растений? А такая энергия, конечно, может быть только духовной энергией, животворящей силой Святого Духа» ${ }^{20}-$ заключает святитель.

В этом же направлении приводит святитель и аргумент чисто естественнонаучного порядка:

...При атомном распаде освобождаются формы энергии все более тонкие,
приближающиеся к чему-то нематериальному. Что же мешает нам сделать
последний шаг и признать существование вполне нематериальной, духовной
энергии и считать её первичной формой, родоначальницей и источником
всех форм физической энергии? Только априорное отрицание Духа и мира
духовного, отрицание упорное и непонятное, ибо огромное количество фак-
тов императивно принуждает нас считаться с ними и признать наряду с ма-
териальной природой безграничный, гораздо более важный мир духовный ${ }^{21}$.

А если данные естественных наук при их развитии приводят нас к признанию существования тонкого, духовного, нематериального мира, то что мешает нам прислушаться к религии, которая всегда это утверждала - а главное, прислушаться к тому, что именно говорит религия об этом духовном мире и к чему, к какой жизни, призывает по этой причине каждого человека.

Вероятно, некоторые аргументы святителя при современном развитии естественных наук уже устарели, но многие - сохраняют свою актуальность и по сей день. В любом случае они заслуживают внимательного осмысления. Однако думается, что в свете изучаемой темы наиболее ценен для нас личный жизненный опыт этого великого святого,

20 Лука (Войно-Ясенецкий), архиеп. Дух, душа и тело. С. 350.

21 Там же. С. 344. 
яркого учёного, великого хирурга и великого человека, совмещавшего в себе преданность религии и приверженность науке и направлявшего свои научные знания на служение вере.

Подытожить хотелось бы словами Н. И. Пирогова, которые в ходе своей работы дважды цитирует свт. Лука и которыми завершает свою брошюру «Наука и религия»:

Веруя, что основной идеал учения Христа, по своей недосягаемости, останется вечным и вечно будет влиять на души, ищущие мира через внутреннюю связь с Божеством, ни на минуту не можем сомневаться в том, что этому учению суждено быть неугасаемым маяком на извилистом пути нашего прогресса ${ }^{22}$.

\title{
Библиография
}

Вебер М. Протестантская этика и дух капитализма // Вебер М. Избранные произведения. М.: Прогресс, 1990. С. 61-272.

Лука (Войно-Ясенецкий), архиеп. Дух, душа и тело // Лука (Войно-Ясенецкий), архиеп. Избранные творения. М.: Сибирская Благозвонница, 2010. С. 325-380.

Лука (Войно-Ясенецкий), архиеп. Наука и религия // Избранные творения. М.: Сибирская Благозвонница, 2010. С. 381-427.

Ньютон И. Толкования на пророчества Даниила и Апокалипсис Иоанна Богослова. СПб.: Пальмира, 2018.

Паскаль Б. Мысли. СПб.: Пальмира, 2017.

\section{St. Luke Voyno-Yasenetsky on Science and Religion}

\author{
Priest Pavel O. Lizgunov \\ $\mathrm{PhD}$ in Theology \\ Vice-rector for Academic Affairs of Moscow Theological Academy \\ Holy Trinity- St. Sergius Lavra, Sergiev Posad 141300, Russia \\ lizgunov@gmail.com
}

For citation: Lizgunov, Pavel O., priest. "St. Luke (Voyno-Yasenetsky) on Science and Religion”. Theological Questions, no. 2 (4), 2020, pp. 62-72 (in Russian). DOI: 10.31802/PWG.2020.4.2.003

Abstract. The article discloses St. Luke's account of the relationships between science and religion, given in his works Spirit, Soul and Body and Science and Religion. St. Luke demonstrates that there are no fundamental contradictions between science and religion, moreover, such 
contradictions are impossible because of very limited overlapping of their domains. He shows that in many respects science and religion complement each other. In his discussion he uses a number of traditional and some original arguments.

Keywords: st. Luke Voyno-Yasenetsky, spirit, soul and body, Christianity, science and religion, apologetics, natural science, vitalism, religiosity of scientists, spiritual world.

\section{References}

Newton I. (2018) Tolkovaniia na prorochestva Daniila i Apokalipsis Ioanna Bogoslova [Observations upon the Prophecies of Daniel and the Apocalypse of St. John: A Commentary on Daniel and Revelation]. Saint Petersburg: Palmira (in Russian).

Pascal B. (2017) Mysli [Pensées]. Saint Petersburg: Palmira (in Russian).

Voyno-Yasenetsky L. (2010) “Dukh, dusha i telo” ["Spirit, Soul and Body”], in Izbrannye tvoreniia [Selected Works]. Moscow: Sibirskaya Blagozvonnitsa, pp. 325-380 (in Russian).

Voyno-Yasenetsky L. (2010) "Nauka i religiia” ["Science and Religion”], in Izbrannye tvoreniia [Selected Works]. Moscow: Sibirskaya Blagozvonnitsa, pp. 381-427 (in Russian).

Weber M. (1990) "Protestantskaia ètika i dukh kapitalizma" ["The Protestant Ethic and the Spirit of Capitalism"], in Izbrannye proizvedeniia [Selected Works]. Moscow: Progress, pp. 61-272 (in Russian). 